\title{
Um debate sobre a descontinuidade temporal: Fernand Braudel, Gaston Bachelard, Gaston Roupnel e Georges Gurvitch
}

\author{
A polemic on temporal discontinuity: Fernand Braudel, Gaston Bachelard, \\ Gaston Roupnel and Georges Gurvitch
}

\author{
André Fabiano Voigt \\ voigtandre@hotmail.com \\ Professor adjunto \\ Universidade Federal de Uberlândia \\ Av. João Naves de Ávila, 2121 - Santa Mônica \\ 38408-144 - Uberlândia - MG \\ Brasil
}

\section{Resumo}

Neste estudo, pretendemos demonstrar que as ideias teóricas de Fernand Braudel acerca da noção de temporalidade se desenvolveram por oposição a algumas teorias da descontinuidade temporal existentes no cenário filosófico francês da década de 1950. Embora tenha usado como exemplo de apologia da descontinuidade o livro La Dialétique de la Durée (1936) de Gaston Bachelard, Braudel esboça também uma crítica às noções de descontinuidade de Georges Gurvitch. Um autor que estará nos bastidores deste breve estudo é o historiador Gaston Roupnel, que é citado

188 de modo elogioso tanto por Braudel quanto por Bachelard. À primeira vista, a rejeição das ideias acerca da descontinuidade temporal por parte de Braudel parece ter sido antes o resultado de uma atitude política do que a tradução de um consenso entre os historiadores do período.

\section{Palavras-chave}

Fernand Braudel; Gaston Bachelard; Descontinuidade.

\begin{abstract}
This study argues that Fernand Braudel's theoretical ideas regarding temporality were developed in contradistinction to a few theories of temporal discontinuity that were available in the French philosophical landscape of the 1950s. Braudel mainly opposed Gaston Bachelard's eulogy of the discontinuity, as conveyed in La Dialétique de la Durée (1936), but also criticized Georges Gurvitch's notions of discontinuity. An author who will be behind the scenes of this short study is the historian Gaston Roupnel, who is quoted, in a laudatory way, both by Braudel and by Bachelard. At first sight, Braudel's rejection of the notions of discontinuity seems to have resulted rather from his own political attitude than from a historiographical consensus on the issue.
\end{abstract}

\section{Keywords}

Fernand Braudel; Gaston Bachelard; Descontinuity.

Recebido em: 11/1/2013

Aprovado em: 9/4/2013

\footnotetext{
* Artigo vinculado ao projeto "Tempo e Escrita: Ritmanálise e Poético-análise em Gaston Bachelard", aprovado pelo Edital 01/2011 da FAPEMIG.
} 


\section{Braudel e Bachelard: um encontro incidental}

Iniciaremos nosso breve estudo a partir de um encontro incidental: aquele entre o historiador Fernand Braudel e o filósofo Gaston Bachelard. A referência mais conhecida que cruza os dois nomes está no célebre artigo de Braudel a respeito da "longa duração" - publicado em 1958 na revista Annales - no qual faz a instigante diferenciação entre o "tempo do historiador" e o "tempo do sociólogo":

Para o historiador, tudo começa, tudo acaba pelo tempo, um tempo matemático e demiúrgico, do qual seria fácil sorrir, tempo como que exterior aos homens, [...]

Os sociólogos, é claro, não aceitam essa noção muito simples. Estão muito mais próximos da Dialectique de la durée, tal como a apresenta Gaston Bachelard. O tempo social é simplesmente uma dimensão particular de determinada realidade social que contemplo (BRAUDEL 2007, p. 72).

Passagem pouco lembrada e pouco celebrada atualmente pelos historiadores - em comparação às sempre repetidas explicações sobre as três abordagens do tempo, englobando estrutura, conjuntura e evento -, esta assertiva de Braudel demarca os contornos de um acirrado debate que envolveu, em momentos das décadas de 1940 e 1950, duas concepções de temporalidade na escrita historiadora: de um lado, a primazia das longas durações das estruturas mentais, em harmonia com as conjunturas sociais e os eventos políticos; de outro, a afirmação da descontinuidade como natureza do tempo e da história.

Destarte, queremos acompanhar os movimentos pelos quais Braudel operacionaliza um complexo jogo de referências intelectuais para delinear seu quadro teórico de pensamento acerca da "Ionga duração", rejeitando as teses da descontinuidade. Trataremos, nestas páginas, de dois autores pouco conhecidos nos dias atuais, os quais levantaram teses acerca da descontinuidade: Gaston Roupnel (1871-1946) - cuja obra teria inspirado a "história estrutural" de Braudel - e Georges Gurvitch (1894-1965), sociólogo/filósofo que discute a descontinuidade temporal em história e em sociologia - e com quem Braudel estabelece um debate na década de 1950, em alguns artigos da revista Annales.

Embora compreendamos que esta questão não está apartada de uma ampla discussão sobre a continuidade/descontinuidade temporal (ocorrida sobretudo no meio acadêmico francês) ${ }^{1}$ da mesma forma como há uma extensa bibliografia que trata do pensamento de Fernand Braudel em comparação com outros autores, ${ }^{2}$ resolvemos adotar um caminho pouco ortodoxo em nosso estudo: fazer dialogar os textos de Braudel com os de um número restrito de autores pouco conhecidos e divulgados no meio acadêmico brasileiro, de modo a entendê-los como acontecimentos singulares e distintos, a partir dos quais as tradicionais noções de "revisão bibliográfica", "contexto" ou mesmo "obra" parecem-nos pouco adequadas. Se colocarmos esta questão em um amplo contexto ou no interior da obra de um autor, torna-se mais difícil notar as disputas

\footnotetext{
${ }_{1}^{1}$ Acerca do tema dos embates teórico-metodológicos mais relacionados ao meio acadêmico francês, ver: REVEL 2010.

2 No meio acadêmico brasileiro há uma considerável bibliografia que discute o tema. Ver: LOPES 2008; REIS 1994; 2004; 2008; RODRIGUES 2009; BARROS 2011.
} 
e decisões realizadas pelos autores aqui mencionados, na medida em que as inserimos em linhas pretensamente contínuas e previsíveis de pensamento. Esta questão nos parece bem mais tortuosa do que gostaríamos de admitir, e a própria escrita deste breve estudo pretende acompanhar as torções e minúcias de uma discussão pontual pouco divulgada em nosso meio.

Mais uma observação é importante de início: não nos cabe fazer aqui, de maneira unívoca, uma definição de continuidade ou de descontinuidade temporal, pois cada autor comentado em nosso estudo trata estes conceitos de maneira singular. Tomar uma referência única de cada conceito seria, a nosso ver, simplificar o problema de modo binário, sem considerar as diversas concepções de continuidade e de descontinuidade entre os autores em discussão. As diversas nuanças de pensamento entre eles colocadas em debate é, portanto, a riqueza deste tema.

Cabe a nós, destarte, julgar qual é a melhor perspectiva de temporalidade? Não acreditamos que julgamentos façam parte de nosso métier. Entretanto, nosso intuito aqui é tornar visível como a rejeição das teses da descontinuidade por Braudel pertence muito mais a uma relação de saber/poder muito singular no interior de sua obra, a qual se torna praticamente invisível quando submetemos as decisões pontuais de um autor à longevidade de sua biografia.

\section{Roupnel e Bachelard: a descontinuidade}

Feitos os devidos esclarecimentos, começaremos nossa investigação com a 190 obra de Gaston Roupnel. Historiador francês, contemporâneo e amigo de Gaston Bachelard, Roupnel escreveu vários livros ao longo de sua vida, englobando diferentes assuntos. Em sua obra, podemos ressaltar a importância de dois livros: Siloë - publicado em 1927 e revisado sob o título de La Nouvelle Siloë em 1945 (ROUPNEL 1945) - e Histoire et Destin, publicado em 1943 (ROUPNEL 1943). O primeiro serviu de inspiração para um livro de Gaston Bachelard, intitulado L'Intuition de I'Instant (BACHELARD 2007), no qual elogia a concepção roupneliana de tempo, centralizada no instante e na descontinuidade, complementado pelo livro La Dialectique de la Durée, em 1936 (BACHELARD 1988). O segundo livro foi objeto de uma cuidadosa resenha que Braudel escreve e publica na revista Mélanges d'histoire sociale em 1944, admirando sua concepção de tempo longo e de "história estrutural" (BRAUDEL 1944).

Neste momento, parece-nos que há uma grave contradição: como seria possível que a obra de um mesmo autor inspirasse duas concepções de tempo tão distintas? Como seria possível conviver, nos escritos de um mesmo autor, a longa continuidade das durações lentas e o instante descontínuo? É a partir desta curiosa questão que iniciaremos nosso trabalho.

Em primeiro lugar, tomados por uma tradição interpretativa que sempre teve necessidade de julgar o passado pela coerência entre autor, obra e época, lemos os dois livros de Roupnel, no intuito de compreender e de, quem sabe, restituir uma verdade acerca de sua obra. Tentação comum, mas sempre vã.

Conseguiríamos, ao restituir o caráter de um autor a partir de sua obra, encontrar qual dos dois teria interpretado mal seus escritos? Teríamos, no 
tribunal da história, um culpado pelo mau uso de um autor? Certamente, não é esse nosso intento. Da mesma forma, seria muito cômodo, a nosso ver, encontrar uma contradição na obra de um autor pouco conhecido para absolver dois autores reconhecidos da possibilidade de má compreensão ou mesmo de má fé. Longe disso.

Preferimos, por outro lado, entender estas duas leituras da obra de Gaston Roupnel como dois acontecimentos distintos, entrecruzados no debate acerca da temporalidade no meio acadêmico francês de meados do século XX. Comecemos, então, pelo trabalho de Bachelard a respeito do livro Siloë, de Roupnel. Embora já tenhamos tratado repetidamente, em nossos estudos anteriores, da minuciosa análise que Bachelard faz do livro de Roupnel, mudaremos um pouco o foco de nossas investigações sobre o tema. ${ }^{3}$

Elogio firme às considerações roupnelianas acerca da natureza do tempo, A Intuição do Instante é um marco na obra bachelardiana. É nele que o autor estabelece uma ideia mais precisa de sua crítica ao conceito de duração, presente nos estudos de Henri Bergson. Ao invés de compreender a natureza do tempo em durações, formando grandes continuidades indivisíveis, Bachelard defende que a natureza do tempo fundamenta-se em instantes, em relação de descontinuidade entre eles (BACHELARD 2007). Entretanto, seu trabalho a respeito da ideia de descontinuidade temporal não se iniciou somente a partir de sua leitura da obra de Roupnel. Em sua tese de doutorado, intitulada Ensaio sobre o conhecimento aproximado (BACHELARD 2004) - defendida em 1927 na França - já apresenta argumentos que questionam a tese da continuidade, sobretudo em sua crítica pontual ao pragmatismo de William James.

Embora concorde com a tese de James no que concerne à descontinuidade conceptual - na qual afirma que "os conceitos formam um sistema essencialmente descontínuo e transpõem o progresso de nossas percepções sensíveis" (BACHELARD 2004, p. 30) -, Bachelard discorda da forma como o autor concebe a continuidade metafórica da relação cognitiva. Se James, por um lado, acredita haver experiências cognitivas intermediárias que se desenvolvem em movimento contínuo até atingir a percepção sensível do objeto, Bachelard, por outro, não acredita haver encadeamento contínuo, pois "sob o descontínuo dos atos, está subentendido o contínuo do possível. A verificação, ao fazer passar o possível do ato, não pode trazer a continuidade" (BACHELARD 2004, p. 269). De qualquer maneira, Bachelard adota como perspectiva a separação entre verdade e realidade, cara ao pragmatismo de James, como uma de suas referências intelectuais de base para sua teoria da descontinuidade na história das ciências.

Assim, ao ler o livro Siloë, de Gaston Roupnel, não inicia ali seus estudos acerca da descontinuidade, mas ganha nele um reforço, sobretudo em sua diferença teórica às teses de Bergson que dizem respeito às relações entre tempo e espaço. De um lado, em Duração e Simultaneidade (1922), Bergson 
afirma que "o tempo real não poderia portanto fornecer o instante; este provém do ponto matemático, isto é, do espaço. $E$, no entanto, sem o tempo real, o ponto não seria mais que o ponto, não haveria instante" (BERGSON 2006, p. 62). De outro, Bachelard afirma, com base nos escritos de Roupnel: "a tese de Roupnel realiza, portanto, a aritmetização mais completa e mais franca do tempo. A duração não passa de um número cuja unidade é o instante. [...] Roupnel diz que 'o Espaço e o Tempo só nos parecem infintos quando não existem'" (BACHELARD 2007, p. 42).

Após ter lido sobretudo o capítulo do livro de Roupnel acerca das relações entre tempo e espaço, Bachelard encontra uma forma de responder à leitura que Bergson faz da teoria da relatividade einsteiniana. Não há tempo sem acontecimentos, não há um tempo vazio e infinito, no qual o espaço deve se adequar. Somente há tempo com seu espaço correspondente, o qual converge no instante como elemento-chave da relação entre ambos. Portanto, o instante torna-se, para Bachelard, o centro de sua fenomenologia temporal. ${ }^{4}$

Roupnel escreve, em Siloë, que é apenas do presente que temos consciência, e que a duração é uma construção artificial, uma trama feita de atos descontínuos (ROUPNEL 1945, p. 147-149). Dessa forma, do ponto de vista da consciência, não é possível demonstrar a duração bergsoniana, mas apenas o instante descontínuo. Assim, Bachelard encontra elementos para sofisticar sua teoria da descontinuidade temporal, situando-a não somente no interior da história das ciências, mas também em relação à memória, à consciência e à criação artística.

Entretanto, em seu elogio a Roupnel, Bachelard faz questão de lembrar o ofício de seu amigo: o de historiador.

Roupnel, como historiador minucioso, não podia ignorar que cada ação, por simples que seja, rompe necessariamente a continuidade do devir vital. Se observarmos a história da vida em seus pormenores, veremos que ela é uma história como as outras, cheias de repetições desnecessárias, anacronismos, esboços, fracassos e recomeços (BACHELARD 2007, p. 28).

Seria esta uma provocação aos historiadores que defendem a continuidade? Talvez. Mas ela foi recebida com silêncio durante muito tempo.

\section{Braudel e Roupnel: história e filosofia?}

Como já afirmamos anteriormente, Gaston Roupnel publica seu último livro em 1943, intitulado Histoire et Destin. Livro de cunho eminentemente teórico, no qual o autor esboça suas considerações acerca da história, da multiplicidade temporal e do valor dos acontecimentos. Ao ser publicado, é lido com interesse por alguns historiadores em sua época. Citaremos apenas dois: Lucien Febvre e Fernand Braudel.

Febvre tinha inicialmente a intenção de fazer a resenha do livro, mas Braudel - que o estava lendo durante sua prisão - perguntou a Febvre sobre

\footnotetext{
${ }^{4}$ Ver, para maiores informações, artigos anteriormente publicados acerca do tema (VOIGT 2010; 2011; 2012).
} 
a possibilidade de fazer-Ihe a resenha (FEBVRE; ROUPNEL 1947, p. 479-481). Febvre aceitou e Braudel publicou a resenha em 1944 na Mélanges de histoire sociale, intitulada Faillité de l'histoire, triomphe du destin?. Nela, Braudel faz um interessante movimento. Na primeira parte, elogia francamente a parte do livro que o agradou:

[...] Mas a maior satisfação que me traz este livro são ainda as páginas densas, inteligentes, que põem em causa uma história de profundeza e das massas: ela se intitula, mui honrosamente, de 'história estrutural'. A história de um povo, escreve ele, determina-se não pelos atos políticos ou militares, mas ao nível do solo, da vida simples. A figura pública e social de um país desenha suas feições sobre a imagem material dos campos e da terra! (BRAUDEL 1944, p. 72).

Coincidentemente ou não, Braudel escreverá em sua tese, concluída em 1946, de uma história "quase imóvel" - relacionada ao meio, à terra, às lentas transformações geográficas - distinta de uma história "tradicional", dos acontecimentos políticos e relacionada aos indivíduos (BRAUDEL 1995, p. 25). Influência dos escritos de Roupnel? Não podemos afirmar com certeza.

Mas nem só de elogios é feita a resenha do livro de Roupnel. A maior parte de seu texto, contudo, é o esboço de uma crítica às afirmações acerca do papel do destino nos acontecimentos da história humana:

O Destino, 'esta respiração do mundo', Gaston Roupnel se compraz, ao fim de sua investigação, ao lhe dizer a importância e os triunfos. Ora, o que é isto, este Destino implacável, que dá um sentido à vida 'dos humanos', das sociedades e dos povos, que é o mais pesado, o mais profundo, o mais original de milhões de peripécias e de existências? (BRAUDEL 1944, p. 75).

Braudel complementa sua crítica mais adiante:

Gaston Roupnel quer nos persuadir, apesar de tudo, que pensemos mais ou menos como ele, nós que buscamos as leis, as explicações, as filosofias da história do mundo, ou que cremos em um Progresso da humanidade, ou em um ideal dominante, nós todos que, de formas diversas, não aceitamos no domínio do humano o reino sem divisão do Acaso [...]. É um perigo de conciliar os inconciliáveis. Mas Gaston Roupnel não queria escapar. Teria ele nos convencido? Esta é uma outra questão.

Quer-se bem acreditar, com ele, que os acontecimentos e os grandes homens deslocam mal o Destino - estes, na estreita medida em que usam seu livre arbítrio [...] Eu sou bastante levado, reconheço, a não superestimar a história acontecimental (BRAUDEL 1944, p. 76).

Ao longo de sua resenha, Braudel deixa escapar um tom ácido e mesmo de desdém às ideias do autor, a despeito de seu elogio à "história estrutural". Aponta em Roupnel uma tendência teológica e mesmo romântica de história, que procura explicar o mundo das ações humanas pelo deus ex machina do destino. Exatamente no momento em que o autor trata dos acontecimentos e do papel do destino na história, Braudel responde esta questão restringindo o pensamento do autor à data de sua escrita: o difícil ano de 1943 que, segundo 
o resenhista, "explica o livro apaixonado de Gaston Roupnel": "é à ocasião dos acontecimentos atuais, sob seu choque, que Gaston Roupnel cedeu à necessidade de explicar a si mesmo e de nos explicar seu ofício, o de historiador" (BRAUDEL 1944, p. 71).

Diante disso, surgem pelo menos duas indagações. Em primeiro lugar, seria possível explicar alguma publicação apenas a partir de sua relação com a época em que foi escrita? Em segundo plano, mas não menos importante: por que as páginas de Histoire et destin a respeito da "história estrutural" não são também resultado do calor do momento, das atribulações dos acontecimentos de sua época? Não nos arriscaremos a responder agora estas difíceis perguntas.

Após o falecimento de Roupnel, em 1946, surgem várias homenagens a ele em alguns periódicos francófonos. Em 1947, a revista Annales publicou uma homenagem ao autor, escrita pelo próprio editor, Lucien Febvre. Neste texto, foi publicada a carta particular que Roupnel escreveu a Braudel, explicitando a característica de seu livro Histoire et destin. Curiosamente, Febvre destaca no conteúdo da carta aquilo que, segundo ele, interessaria aos historiadores que leram a resenha de Braudel, sobretudo no que tange à relação entre a escrita do livro e sua época. Roupnel, em carta de agradecimento, concorda com Braudel que seu livro tem também uma história: foi escrito entre os anos de 1940 e 1942, tomado pelo pânico de ver a França tomada pela Alemanha,

Aqueles dias atrozes!... Sobre meus velhos dias, aos infortúnios irremediáveis da vida privada, aliou-se o sentimento do infortúnio público nacional $[\ldots]$

Por cólera e despeito comecei a escrever esta primeira parte, cujo tom panfletário e a maneira crítica foram frequentemente ofendidos e desiludidos (FEBVRE; ROUPNEL 1947, p. 481).

Entretanto, em meio a própria imprevisibilidade dos acontecimentos da Segunda Guerra, Roupnel muda o tom do livro:

A entrada da Rússia na guerra trouxe-me súbita esperança. O milagre não atendido havia chegado. E é um outro homem que escreveu a segunda e terceira - e última - partes do livro. O Sr. se espantaria que ele sentiu inclinar-se sobre si e os outros uma 'Providência' protetora dos destinos humanos? (FEBVRE; ROUPNEL 1947, p. 481)

E, por último, dá a Braudel uma humilde resposta à acusação de querer "conciliar os inconciliáveis": "E, a despeito do que pude escrever ou pensar, sinto-me perto daqueles que acreditam no esforço humano. Se os céus têm seu mistério, a desértica sequidão terrestre tem sua estoica grandeza. E continuo a pensar que os 'inconciliáveis' ocultam nossa sabedoria" (FEBVRE; ROUPNEL 1947, p. 481).

Parece-nos, aqui, que Roupnel não poderia descartar os acontecimentos e sua imprevisibilidade na escrita de seu livro - poderia alguém se situar em uma temporalidade "fora do tempo" para escrever um livro? Entretanto, vemos que as atribulações de uma época não são o recurso interpretativo utilizado 
para analisar outros livros de Roupnel, sobretudo aqueles que mais agradam ao espírito dos Annales. Roupnel foi lembrado, em vários necrológios publicados entre 1946 e 1949 - sobretudo o escrito por Lucien Febvre - como o historiador que escreveu Histoire de la Campagne Française (1932), dedicado a uma abordagem criteriosa de história social, que fez Febvre sentir "um tal perfume de bosques e de campinas de terras recentemente remexidas e de vinhas em flor" (FEBVRE; ROUPNEL 1947, p. 479), logicamente associando-o a uma escrita de história ligada às longas durações da terra - e não ao acaso e à descontinuidade dos acontecimentos.

Como Febvre considera, então, a narrativa acerca do tempo descontínuo escrita por Roupnel em Siloë? Na categoria de "livros filosóficos" (FEBVRE; ROUPNEL 1947, p. 480), isto é, realizando uma separação entre o "trabalho de historiador" e o "trabalho de filósofo" na obra de Roupnel. Considerando que, para nosso estudo, é pouco elucidativa a caracterização de uma unidade da obra deste historiador, não seria possível, por outro lado, concordar com Febvre que a interpretação da obra de Roupnel se dá mediante uma clara distinção entre os "livros de história" e os "livros filosóficos". Esta separação realizada por Febvre é um acontecimento à parte da obra de Roupnel. Independentemente do escopo de sua obra, a interpretação realizada pelo então editor da revista Annales é um movimento que não pertence à obra de Roupnel, mas à consolidação de uma visão de história defendida pelos historiadores ligados ao conhecido periódico francês. Portanto, ousamos afirmar que a franca apologia às continuidades e longas durações como características sine qua non do ofício de historiador, relegando ao trabalho do filósofo a análise dos acontecimentos a partir da descontinuidade temporal, é apenas um posicionamento muito específico de Braudel e Febvre, o qual não deve ser objeto de generalizações apressadas por parte dos historiadores.

Após o necrológio escrito por Febvre, repete-se, curiosamente, esta chave interpretativa para a obra roupneliana. Vejamos um exemplo. No ano de 1949, na Revue belge de philologie et d'histoire, Bartier publica uma homenagem a Roupnel (BARTIER 1949, p. 553-554), na qual o autor é lembrado como aquele que, ao escrever Histoire et Destin, combateu vigorosamente a "história historizante" e o estudo do acontecimento, demonstrando ser um defensor da "história estrutural" (BARTIER 1949, p. 553). Ademais, elogia seus trabalhos históricos como a Histoire de la Campagne Française, e afirma que "Gaston Roupnel não brilhou somente como historiador. Ele fez obras de romancista com Nono e Le Vieux Garain, e de filósofo com Siloë e La Nouvelle Siloë" (BARTIER 1949, p. 554).

Novamente, a obra de Gaston Roupnel foi devidamente selecionada nas partes que são mais condizentes com o espírito de um grupo de pesquisadores, os quais elogiam Histoire et destin apenas como uma obra dedicada à "história estrutural", além de delimitar obras como Siloë e La Nouvelle Siloë como trabalhos de filosofia.

Entretanto, quando a obra de Gaston Roupnel é relembrada nos anos seguintes, há uma retomada da polêmica acerca de sua abordagem dos 
acontecimentos e das descontinuidades. Em 1966, Jacques Le Goff escreve uma homenagem a Ferdinand Lot - um historiador que foi considerado um dos inspiradores dos editores da revista Annales, desde 1929. Neste artigo, um curioso trecho retoma a polêmica acerca da obra de Roupnel:

Ferdinand Lot raramente exprimiu sob a forma de princípios sua concepção de história, e quando ele esteve o mais próximo de fazê-la, por exemplo, em sua resenha do livro de Roupnel, Histoire et Destin, fê-la por insistir sobre a importância do quadro cronológico constituído pelos 'acontecimentos', sobre o papel dos indivíduos marcantes, criadores de 'descontinuidades', - ideias as quais não tem um lugar de escolha no espírito dos Annales.

Meu objetivo não é nem o de tomar emprestado Ferdinand Lot para os Annales, para fazer dele um membro insuspeitado e inconsciente de seu grupo - essas conversões póstumas e forçadas sempre são muito desagradáveis - nem o de julgar a obra de Ferdinand Lot pela medida dos Annales, erguida no padrão do valor histórico. É só o de observar determinados encontros, algumas convergências, que permitam melhor destacar aspectos essenciais do legado científico de Ferdinand Lot (LE GOFF 1966, p. 1180-1181).

Notamos aqui, mais uma vez, um movimento típico dos membros deste renomado periódico francês. Ao reconhecer a obra de um historiador, há um cuidado minucioso para selecionar quais são os pontos de convergência que o colocam à imagem e semelhança dos Annales, e há, do mesmo modo, um significativo empenho em deixar bem claros os limites que o distanciam do grupo, sobretudo quando sua perspectiva de história considera eminentemente o papel dos acontecimentos e das descontinuidades. É importante esclarecer que Ferdinand Lot publicou boa parte de sua obra durante as últimas décadas do século XIX e as primeiras do século $X X$, fato que o distancia sobremaneira do debate mais acalorado acerca do papel da descontinuidade temporal, como o estabelecido pela leitura que Bachelard realiza de aspectos da obra de Roupnel.

Enfim, quando Lot considerou a possibilidade de publicar na revista Annales um artigo/resenha de Histoire et destin como uma homenagem a Marc Bloch - cuja intenção era colocar Bloch lado a lado com Roupnel, em uma apologia à relevância dos acontecimentos e das descontinuidades na história -, Lucien Febvre informa a Ferdinand Lot, em uma carta datada de 24 de janeiro de 1945, que esta resenha já teria sido escrita por Fernand Braudel para a revista. Na mesma carta, Febvre teve o cuidado de explicar as divergências entre Marc Bloch e Roupnel, afirmando que "Bloch detestava a história de Roupnel" (LE GOFF 1966, p. 1180, nota 3).

Além das observações colocadas aqui, podemos inferir um dado precioso acerca da leitura da obra de Roupnel entre os historiadores: não havia um consenso acerca de seu trabalho. Se ele foi realizado, deve-se à perpetuação da leitura efetuada pelos principais historiadores ligados à revista Annales, que dividiu a obra roupneliana em duas partes bem precisas: a) em seus livros "de história", Roupnel figura como um exemplo de abordagem dentro da história social - relacionada às longas durações e à materialidade geográfica; b) 
suas palavras em defesa da descontinuidade e do papel dos acontecimentos pertencem, por outro lado, a seus livros "de filosofia".

\section{Braudel e Gurvitch: história e sociologia}

O empenho dos historiadores dos Annales em apagar quaisquer rastros de uma interpretação de Roupnel como um historiador que elogia a descontinuidade temporal e o acaso dos acontecimentos foi, digamos, bem-sucedido. Fica mais fácil agora notarmos por que, em seu famoso artigo de 1958 sobre a "longa duração", Braudel está novamente preocupado em demarcar a distância entre o "tempo do historiador" e o "tempo do sociólogo", citando como exemplo do segundo o livro A dialética da duração, de Bachelard - desta vez, contra os estudos de Georges Gurvitch.

Por que Braudel não cita o livro $A$ intuição do instante, de Bachelard? Talvez porque encontraríamos nele um Gaston Roupnel pouco afeito às longas durações? Quiçá porque veríamos nele uma provocação aos historiadores que defendem os tempos longos? Mais perguntas para as quais não ousaríamos dar uma resposta definitiva.

De qualquer maneira, Braudel toma A dialética da duração de Bachelard como exemplo de temporalidade, desta vez para os sociólogos, como resposta à tese de Georges Gurvitch sobre a descontinuidade. É importante esclarecer, de início, que Gurvitch não foi um discípulo de Bachelard, mas sim, um pensador que estava em um círculo de intelectuais europeus que trabalhavam aspectos da fenomenologia alemã. ${ }^{5}$ Talvez seja possível aproximar o pensamento de Bachelard e o de Gurvitch pelo interesse comum pela fenomenologia e, obviamente, pela questão da descontinuidade. Entretanto, também não há registros de um eventual diálogo intelectual entre ambos ou mesmo de que se conheceram.

O interesse de Braudel em realizar um estudo sobre Gurvitch aparece pela primeira vez em 1953, quando publica o artigo "Georges Gurvitch ou la discontinuité du social na revista Annales", no qual critica aspectos do livro Vocation actuelle de la sociologie, publicado em 1950. Nele, Braudel expressa inicialmente um juízo de valor que tenta resumir o trabalho de Gurvitch: "Georges Gurvitch adora destruir. Ele o faz com uma espécie de entusiasmo" (BRAUDEL 1953, p. 348). Mais adiante, Braudel expõe claramente seu combate contra a noção de descontinuidade apontada por Gurvitch:

Ora, se a história é assim descontínua, fragmentada, todas as ciências sociais preocupadas em compreender o atual sentem, depois deste instante presente que elas observam, tantas rupturas e falhas precedentes que elas são como que isoladas na breve realidade viva... Enclausuradas. Prisioneiras. O presente é uma realidade quase autônoma. Todo um anti-historicismo vigia e castiga as ciências sociais. Estão na impossibilidade de utilizar o passado, de se alimentar dele (BRAUDEL 1953, p. 349).

\footnotetext{
${ }^{5}$ Podemos destacar um de seus trabalhos, Les tendances actuelles de la philosophie allemande: E. Husserl, M. Scheler, E. Lask, N. Hartmann, M. Heidegger, publicado em Paris no ano de 1930, o qual foi prefaciado pelo filósofo Léon Brunschvicg, com quem Gaston Bachelard mantinha constantes diálogos intelectuais. Disponível em: http://www.worldcat.org/title/tendances-actuelles-de-la-philosophie-allemande-e-husserl-m-scheler-elask-n-hartmann-m-heidegger/oclc/491101532. Acesso em: 21 set. 2012.
} 
Talvez Braudel tenha exagerado em sua crítica. A descontinuidade temporal não significa, nem para Bachelard e nem para Gurvitch, o estabelecimento de um reinado absoluto do presente ou a constatação da impossibilidade de usar o passado. Parece-nos que a descontinuidade seria - pelo menos nos trabalhos de história das ciências escritos por Bachelard - um modo de pensar os acontecimentos em sua singularidade, em sua espacialidade própria, considerando os eventos anteriores não como causas que the expliquem, mas como obstáculos que precisaram ser superados, retificados (BACHELARD 2004). Quanto à ideia de descontinuidade em Gurvitch, trataremos dela mais adiante, ainda neste artigo.

Antes, é importante trazermos aqui a resposta que Braudel dá às teses da descontinuidade, demonstrando que não vê a sociedade e a história de modo unilinear:

Na verdade, o que afirma Georges Gurvitch, após quaisquer outros dizemos após Marx como após Proudhon ou Harriou - é que a sociedade não é unilinear, de uma só e simples torrente [...] Do mesmo modo, pensamos, a história não é unilinear. Isso é o que já havia ensaiado, por minha conta, de dizer e de apreender falando da história semi-imóvel, da história lenta, da história acontecimental, ou melhor, de superfície. O que traduzi, nada menos que geometria no espaço, a inquietação de movimentos de duração diferentes. [...] Portanto, a história, ela não mais, não nos aparece como unidimensional (BRAUDEL 1953, p. 354-355).

O famoso historiador dos Annales não entende, portanto, a sociedade e a história como unilineares. Contudo, em sua divisão temporal em três níveis, não é possível vislumbrar - a partir dos próprios argumentos do autor - uma perspectiva de unificação de todos os três no tempo longo, encravado na superfície da terra, "quase fora do tempo" (BRAUDEL 1995, p. 25), tocando na eternidade? Esta visão difere muito, destarte, da ideia de descontinuidade levantada por outros autores.

Vamos, enfim, à visão de Gurvtich. Em artigo publicado na revista Annales em 1957, intitulado Continuité et discontinuité en histoire et en sociologie, o autor publica o artigo - oriundo de uma conferência - na seção Débats et combats do periódico, em que expõe sua interpretação acerca do assunto. De um modo bem distinto da afirmação levantada por Braudel, a argumentação de Gurvitch parece bem cuidadosa. Em primeiro lugar, afirma que não se trata de colocar, de modo simplista, que a história deva ser descontínua e tratar dos acontecimentos e que a sociologia deva ser contínua e abordar as instituições. Isto seria colocar uma alternativa falsa, pois história e sociologia possuem, para o autor, o mesmo domínio, isto é, o que chama de fenômenos sociais totais um conceito central para a tese de Gurvitch (GURVITCH 1957, p. 73-74). Para o autor, estes fenômenos são sempre "vulcânicos", "ao Ihes examinar a todos os seus patamares em profundidade e sob todos seus aspectos e escalas, e aos quais participam os homens totais, cuja divisão em homens econômicos, políticos, morais, religiosos, etc., não faz sentido" (GURVITCH 1957, p. 73-74).

Ora, se a história e a sociologia têm o mesmo domínio, a diferença entre ambas estaria, a princípio, no método. O autor explica esta diferença: 
O método da sociologia é tipológico, o da história é individualizante: [...] Do ponto de vista do método, a sociologia é obrigada a acentuar a descontinuidade dos tipos, das escalas e, finalmente, das relações entre os fenômenos sociais totais e suas estruturas, sem falar da descontinuidade das temporalidades e das escalas de tempo. A história, ao contrário, sob o ângulo do método, é conduzida a preencher as rupturas, a juntar os pontos entre os tipos sociais que ela singulariza e individualiza ao limite, a passar sem solução de continuidade das estruturas globais aos próprios fenômenos sociais globais, reconstruindo a continuidade do tempo. Do ponto de vista do método pode-se afirmar, portanto, que a história é bem mais continuista que a sociologia, e a tese mais ou menos admitida deve ser invertida (GURVITCH 1957, p. 74).

Todavia, além das diferenças de método, Gurvitch vê entre a história e a sociologia, diferenças entre a realidade histórica e a realidade social:

O paradoxo é o seguinte: se o método e objeto da história, segundo nossa característica, parecem mais continuistas que os da sociologia, a realidade histórica, ao contrário, parece se revelar mais descontínua que a realidade social. [...] Bem entendido, trata-se de pôr fim a esta confusão abusiva entre historiografia (ou ciência da história) e realidade histórica, confusão a qual se tornam responsáveis tanto historiadores, os quais vêm direta ou indiretamente de Comte ou de Hegel (GURVITCH 1957, p. 75).

Vejamos, mais adiante, como o autor observa esta questão entre Comte e Hegel:

Comte identificou a realidade histórica com o desenvolvimento, com a evolução, com o progresso unilinear e ao mesmo tempo espiritual e material; estudando esta realidade histórica, a sociologia foi identificada com a filosofia positiva que põe em relevo este processo e the dá um sentido consciente e um método. De seu lado, Hegel identificou a realidade histórica com o Estado, o Destino, o advento do Espírito absoluto, por intermédio do espírito objetivo e subjetivo, dando à realidade histórica um sentido ao mesmo tempo mais místico e mais dramático que Comte, mas, como ele, fazendo surgir o método da história tanto quanto ciência da realidade histórica, cujo resultado é a filosofia de Hegel que torna consciente o sentido da história (GURVITCH 1957, p. 75-76).

E conclui:

Nos dois casos, estamos na presença da identificação da história como realidade e da história como historiografia à base de uma filosofia dogmática da história, que conhece por antecipação seu próprio sentido. Mas a filosofia da história se mostra a pior inimiga da realidade histórica quanto da ciência da história e das duas combinadas, destruindo seu fundamento e retirando toda significação tanto do estudo histórico quanto da própria realidade histórica (GURVITCH 1957, p. 76).

Após estas longas citações que fizemos de Georges Gurvitch, fica evidente que o autor estabelece uma distinção clara entre realidade histórica e historiografia. Neste interstício, aponta uma operação que os historiadores não costumam reconhecer em seus ofícios: a de construir um relato contínuo a partir de uma realidade descontínua, anacrônica, destituída de um sentido a 
priori. Embora também seja evidente que as argumentações de Bachelard e de Gurvitch são distintas, podemos aproximá-las cuidadosamente em um ponto em que tratamos no início de nosso estudo, a saber: quando Bachelard faz um elogio ao Roupnel de Siloë, afirmando que a história de uma vida, olhada de perto, é cheia de "repetições desnecessárias, anacronismos, esboços, fracassos e recomeços". Em outros termos, pode-se perceber em ambos uma diferença entre a realidade histórica descontínua e a forma pela qual os historiadores traçam, artificialmente, uma linha de corte na descontinuidade dos eventos, construindo-Ihes um sentido. Entretanto, Gurvitch faz uma crítica direta à filosofia hegeliana da história, que antecipa o sentido da história, procurando igualar realidade histórica e historiografia em uma mesma trama, atribuindo-Ihe o caráter de verdade dogmática na organicidade do tempo.

Braudel, que não destrona o tempo - mesmo que geografizado - como noção unificadora da experiência e do sentido, também rejeita a tese de Gurvitch, atribuindo-Ihe o caráter de destruidor e anti-historicista. O historiador dos Annales chega a ser tão cuidadoso em neutralizar os argumentos de seu opositor que faz uma introdução ao artigo de Gurvitch, colocando seu posicionamento de antemão. Vamos reproduzir aqui um trecho curioso:

Faz-se necessário dizer: nem Lucien Febvre, nem eu estamos completamente de acordo com nosso simpático colega. Os historiadores compartilharão, sem dúvida, do nosso ponto de vista. Onde Georges Gurvitch procura as diferenças, os desacordos, nós vemos sempre as analogias, os encontros e um trabalho em comum. História e Sociologia não são, para nós, o avesso e o reverso de uma mesma matéria, mas esta matéria em toda a sua espessura e em todos os seus delineamentos... (BRAUDEL in GURVITCH 1957, p. 73).

O que mais chama a atenção na afirmação de Braudel é o seu apelo direto aos historiadores: que todos concordem com ele, rejeitando de antemão os argumentos de Gurvitch! Seria este um desesperado recurso ao argumento de autoridade? Não saberíamos dar, novamente, uma resposta direta a tão constrangedora pergunta.

\section{Um possível reencontro entre Braudel e Bachelard}

No caloroso debate entre a continuidade e a descontinuidade em história, o editor da revista Annales disputou, milímetro a milímetro, seu posicionamento a favor das longas durações, do tempo encravado na superfície da terra e do mar, tentando neutralizar a todo custo opositores de grande mérito acadêmico, como Roupnel, Bachelard, Ferdinand Lot e, posteriormente, Georges Gurvitch. Não é à toa que, em seu texto eminentemente político sobre a longa duração, Braudel trata dos argumentos de Gurvitch em tom professoral e mesmo indulgente, certo de que o silêncio seria estabelecido definitivamente entre os historiadores que defendem a descontinuidade temporal. Por isso, vemos que o breve encontro entre Gaston Bachelard e Fernand Braudel foi tão somente uma luta indireta, difusa pela luz de outros opositores. 
Como pudemos perceber, não há, portanto, um confronto direto entre o professor de história das ciências de Sorbonne e o editor da revista Annales, mas uma breve citação que é o marco de uma verdadeira maquinaria discursiva: a reivindicação da continuidade temporal como característica eminente do ofício de historiador contra as várias constatações da descontinuidade como realidade do tempo e da história. De um modo geral, parece-nos que, após a operação discursiva dos Annales, pouco foi publicado entre os historiadores acerca da descontinuidade. Contudo, é possível ver, no longínquo horizonte da filosofia, um novo lampejo de defesa da descontinuidade, contra as longas durações.

Apesar dos trabalhos de Georges Canguilhem realizados durante as décadas de 1940 e 1950, nos quais questiona a continuidade dos conceitos científicos, ${ }^{6}$ será a partir de uma crítica à abordagem dedicada às longas durações, realizada por Michel Foucault em A Arqueologia do Saber (1969), que se põe novamente em ênfase a questão da descontinuidade entre a história e a filosofia, pela via da história das ciências. Em meio aos argumentos de Foucault, vemos uma referência pelo menos intrigante: ele retoma, entre outras referências acerca da descontinuidade, os conceitos de atos e liminares epistemológicos, retirados da obra epistemológica de Bachelard, para fundamentar sua tese sobre a descontinuidade na história das ciências e dos saberes (FOUCAULT 2004, p. 4).

Terminamos nosso estudo voltando, curiosamente, ao início. Braudel e Bachelard, em seu fortuito e pouco comentado encontro em 1958, entram novamente no caloroso debate entre a continuidade e a descontinuidade em 1969, mas, desta vez, em meio às brumas da escrita de um autor que causará mais impacto entre os historiadores, apesar de sua designação geral de "filósofo".

\section{Referências bibliográficas}

BACHELARD, Gaston. A dialética da duração. São Paulo: Ática, 1988.

. A intuição do instante. Campinas: Verus, 2007.

Ensaio sobre o conhecimento aproximado. Rio de Janeiro: Contraponto, 2004.

BARROS, José D'Assunção. Fernand Braudel e a geração dos Annales. Revista Eletrônica História em Reflexão, Dourados, v. 6, n. 11, jan. - jun. 2012, p. 1-18.

BARTIER, J. Gaston Roupnel. Revue belge de philologie et d'histoire. Tome 27, fasc. 1-2, 1949, p. 553-554. Disponível em: http://www.persee.fr/web/ revues/home/prescript/article/rbph_0035-0818_1949_num_27_1_5356. Acesso em 7 set. 2012.

BERGSON, Henri. Duração e simultaneidade. São Paulo: Martins Fontes, 2006.

\footnotetext{
${ }^{6}$ Ver os trabalhos: Essai sur quelques problèmes concernant le normal et le pathologique, publicado por Canguilhem em 1943 (livro traduzido para o português a partir da edição francesa revisada de 1966, sob o título de O normal e o patológico) e La connaissance de la vie, de 1952.
} 
BRAUDEL, Faillité de l'histoire, triomphe du destin? Mélanges d'histoire sociale, Paris, no 6, 1944, p. 71-77. Disponível em: http://www.persee.fr/ web/revues/home/prescript/article/ahess_1243-2571_1944_num_6_1_ 3132. Acesso em: 7 set. 2012.

. Georges Gurvitch ou la discontinuité du social. Annales: économies, sociétés, civilisations. Paris, ano 8, no 3, 1953. Disponível em: http://www. persee.fr/web/revues/home/prescript/article/ahess_0395-2649_1953_ num_8_3_2187. Acesso em 9 jan. 2013.

. História e Ciências Sociais: a longa duração. In: . Escritos sobre a História. São Paulo: Perspectiva: 2007, p. 41-78.

. O Mediterrâneo e o mundo mediterrânico na época de Filipe II. Lisboa: Dom Quixote, 1995.

FEBVRE, Lucien; ROUPNEL, Gaston. Les morts de I'histoire vivante: Gaston Roupnel. Annales: économies, sociétés, civilisations. Paris, n. 4, 1947, p. 479-481. Disponível em: http://www.persee.fr/web/revues/home/ prescript/article/ahess_0395-2649_1947_num_2_4_3339. Acesso em: 30 ago. 2012.

FOUCAULT, Michel. A arqueologia do saber. Rio de Janeiro: Forense Universitária, 2004.

GURVITCH, Georges. Continuité et discontinuité em histoire et em sociologie. Annales: économies, sociétés, civilisations. Paris, ano 12, n.1, p. 73-74, 1957. Disponível em: http://www.persee.fr/web/revues/home/prescript/ article/ahess_0395-2649_1957_num_12_1_2602. Acesso em 11 jan. 2013.

LE GOFF, Jacques. Ferdinand Lot et les Annales. Annales: économies, sociétés, civilisations. Paris, ano21, n. 5, 1966, p.1180-1181. Disponívelem: http://www. persee.fr/web/revues/home/prescript/article/ahess_0395-2649_1966_ num_21_5_421469. Acesso em 7 set. 2012.

LOPES, Marcos Antônio (org.). Fernand Braudel: tempo e história. Rio de Janeiro: FGV, 2008.

REIS, José Carlos. Nouvelle histoire e tempo histórico: a contribuição de Febvre, Bloch e Braudel. São Paulo: Ática, 1994.

A Escola dos Annales, a inovação em história. $2^{a}$ edição. São Paulo: Paz e Terra, 2004.

. História da História (1950/60). História e Estruturalismo: Braudel versus Lévi-Strauss. História da Historiografia, Ouro Preto, n. 1, ago. 2008, p. 8-18.

REVEL, Jacques. História e Historiografia: exercícios críticos. Curitiba: EDUFPR, 2010.

RODRIGUES, Henrique Estrada. Lévi-Strauss, Braudel e o tempo dos historiadores. Revista Brasileira de História, São Paulo, v. 29, n. 57, jun. 2009, p. 165-186. 
ROUPNEL, Gaston. La nouvelle Siloë. Paris: Grasset, 1945.

Histoire et destin. Paris: Grasset, 1943.

VOIGT, André Fabiano. Gaston Bachelard e Michel Foucault: a linguagem, o tempo e o espaço. Fênix, Uberlândia, v. 8, 2011, p. 1-15. Disponível em: http://www.revistafenix.pro.br/PDF26/Dossie_01_Andre_Fabiano_Voigt. pdf. Acesso em: 25 mar. 2013.

. História e Ficção: Gaston Bachelard e o instante poético. In: RAMOS, Rosângela P.; DA COSTA, Cléria B. (orgs.). Anais V Simpósio Nacional de História Cultural. Brasília 50 anos - Ler e Ver: paisagens subjetivas e paisagens sociais. Brasília: MB2 Produção Gráfica e Editora, 2010, v. 1, p. 1-10.

. Ritmanálise e poético-análise em Gaston Bachelard: a palavra literária e a história. In: CASTELO BRANCO, Edwar de Alencar; MONTEIRO, Jaislan Honório (orgs.). História, arte e invenção: narrativas da história. 1ed. Teresina: Editora da Universidade Federal do Piauí, 2012, v. 1, p. 21-30. 